\title{
Synchronizing phasor measurement and STATCOM controller in power system stability enhancement
}

\author{
Debasish Mondal \\ Department of Electrical Engineering, RCC Institute of Information of Technology, India
}

\begin{tabular}{|c|c|}
\hline Article Info & ABSTRACT \\
\hline & \multirow{11}{*}{$\begin{array}{l}\text { The objective of this paper is to present the concepts of synchronizing phasor } \\
\text { measurement (SPM) and its strategic application in addition with a } \\
\text { STATCOM controller for augmentation of dynamic stability in a multi- } \\
\text { machine power network. The bus voltages of the power network under } \\
\text { consideration are estimated in the form of digital signal by a synchronizing } \\
\text { phasor measurement unit (SPMU). The output of the PMU is then applied to } \\
\text { a fixed structure PI type lead-lag digital STATCOM controller in order to } \\
\text { study the performance of this discrete-time digital control in comparison to } \\
\text { its analog counterpart for the present control problem. The parameters of the } \\
\text { analog controller are first tuned with a popular soft computation technique, } \\
\text { particle swarm optimization (PSO) and later this controller is converted to } \\
\text { digital one for simulation with sampled data outputs received from SPMU. } \\
\text { The validation and effectiveness of the design of the proposed control } \\
\text { scheme is illustrated through time domain simulation of a proposed 3- } \\
\text { machine, 9-bus test power system. The simulation results of the machine } \\
\text { speed deviation response established that the SPM based digital control } \\
\text { system is more effectual and resulting better performance than the } \\
\text { continuous-time analog control system in power system stability } \\
\text { improvement. }\end{array}$} \\
\hline ed Sep 10, 2019 & \\
\hline Revised Feb 19, 2020 & \\
\hline d Jun 7, 2020 & \\
\hline Keywords: & \\
\hline Particle swarm optimization & \\
\hline Phasor data concentrator & \\
\hline Phasor measurement unit & \\
\hline Power system stability & \\
\hline Synchronous compensator & \\
\hline Wide area control & \\
\hline
\end{tabular}

This is an open access article under the CC BY-SA license.

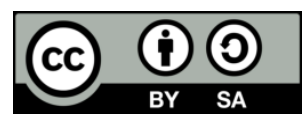

Corresponding Author:

Debasish Mondal

Department of Electrical Engineering

RCC Institute of Information of Technology

Canal South Road, Beliaghata, Kolkata-700015, India

Email: mondald4791@gmail.com

\section{INTRODUCTION}

The problem of small signal stability in power systems is a long standing issue to the researchers. Power system stabilizers (PSSs) [1] are widely used in power industries to maintain the stable operation of power systems following small and large disturbances. With ever growing changes in global economic scenario, the demand of power generation and the stress over the power networks are rising increasingly. Therefore, the uses of the modern controlling devices, FACTS [2-4] are remarkably taken into account, because of its reliable, fast and economic operation. Static synchronous compensator (STATCOM) is an important member in the FACTS groups that are evident to be robust and effectual to mitigate operational difficulties in power networks [5-7].

It is well established that the constraints of analog controllers can be get rid of by utilizing digital signal processing (DSP) based controllers whose operations are programmable, precise and can be easily upgraded by employing high speed, sophisticated hardware. A number of investigations on digital control schemes for power system operations and control are reported in the literature $[8,9]$. The concepts of DSP based measurement of voltage and current phasor are introduced in early eighties [10, 11]. After that it is 
increasingly used by the researchers. In modern smart grid scenario digital signal processing based phasor measurement technology plays a key role in power system monitoring, control and protection [12-14].

The problem of design of any controller is the complication of its right tuning. The tuning required prior knowledge of the operational behaviour of the system. It has also inherent cost of solving difficulties and burden. Some global search evolutionary algorithms such as fuzzy logic control, genetic algorithm (GA) based fuzzy control, artificial neural network (ANN), particle swarm optimization (PSO) etc. have been utilized to design and investigate many power system optimization problems [15-17]. Among these techniques, PSO is being increasingly used by the researchers recently [18, 19]. PSO bears robustness and stability property and also has speedy convergence profile than other available techniques of optimizations. The benefits of PSO compared to GA are that the 'crossover' and 'mutation' operations are not required in PSO.

The huge expansion of power networks and its complexity impel the power system researchers towards the great challenge in terms of grid stability, security and safety, which introduces the concept of wide area monitoring (WAM) and control. In WAM systems it is possible to operate and control the grid satisfactory to save power systems from major blackout. SCADA systems are suitable only for local monitoring and control in a power network with high data latency. However, synchronizing phasor measurement unit (SPMU) is one of the important equipment for WAM and control of power systems with high degree potential and accuracy. It is a sophisticated monitoring device that can measure the instantaneous voltage, current and frequency at any specific locations on the grid and gives real-time data of the system which allows making decisions to prevent power outage and severe blackout.

Several investigations have been carried out by the power system researchers in this direction. The application of PMU for wide area monitoring and control system has been shown in [20]. The location of PMU in a grid is another important aspect. Many researchers have focused their work on optimal placement of PMU. The [21] presents a non-linear programming-based model for the optimal placement of phasor measurement units based on full system observability and to maximize the measurement redundancy at all buses in a power system. Taxonomy for optimal placement of phasor measurement unit has been reported in [22]. This paper offers a unifying description of a relatively large number of works devoted in this issue. Attempts also have been made to apply heuristic optimization method. In [23] a recursive Tabu search method has been employed in finding optimal location of PMU. The method of binary particle swarm optimization has been applied in [24] in order to find optimal PMU location for power system observability considering measurement redundancy.

In view of the above importance in critical service of PMU author has motivated to expedite the work on application of synchrophasor and its related aspects. In this paper author has shown the strategic application of SPMU and digital STATCOM controller for the purpose of mitigating transient stability problem in a multimachine power network. A heuristic optimization method PSO has been implemented to get the optimal values of the variables of a PI type lead-lag STATCOM controller. This analog controller is converted to digital one (z-domain) via Tustin's transformation to adopt digital signal generated from phasor measurement unit. The voltage phasor of local substations are considered to be measured by the PMU. The DSP based outputs of the PMU are then employed to the discrete-time STATCOM controller. It has also been assumed that the communication between the STATCOM controller and the SPMU are based on global positioning systems (GPS) technology via wide area communication network (WAN). As far as author's knowledge is concerned the proposed scheme of application digital control in association with phasor measurement strategy has not been addressed so far in the existing literatures.

The content of the paper is oriented as follows: In section 2 the concepts of synchronizing phasor measurement and the PMU has been described. The construction of conventional STATCOM controller via PSO in association with multimachine modelling and the configuration of digital controller have been demonstrated in section 3. Finally, act and effectiveness of the suggested DSP based control with respect to the continuous-time analog control has been looked over in section 4 and conclusions are drawn in the last section.

\section{SYNCHRONIZING PHASOR MEASUREMENT}

\subsection{Phasor measurement concepts}

A phasor is a unique complex quantity, used to represent graphically a pure sinusoidal waveform. A pure sinusoidal signal can be represented by (1).

$$
X(t)=X_{\max } \cos (\omega t+\varphi)
$$

The phasor of (1) can be written as: 


$$
X(t)=\frac{X_{\max }}{\sqrt{2}} e^{j \varphi}
$$

In order to measure the quantity as a bus voltage the (2) can be written as:

$$
V(t)=\frac{\left|V_{\max }\right|}{\sqrt{2}} e^{j \varphi}
$$

A continuous or constant phasor means a persistent waveform but the signals under investigation are not practically remain persistent, their frequency also variable and may contain harmonic or non-harmonic components. The task of a PMU is to extract the fundamental part and computes its phasor over a finite data set in one period of the fundamental frequency of the input signal. The commonly employed method for estimation of phasor is the utilization of the sampled data input signal, and the application of discrete fourier transform (DFT) on it. If $V(n)\{n=0,1,2, \ldots N-1\}$ are the $N$ samples of the input signal $V(t)$ at $t=$ $n \tau$,where $\tau$ is the sampling interval taken over 1 period of the normal frequency of the power system, then the phasor representation is given by [25].

$$
V_{k}=\frac{1}{\sqrt{2}} \frac{2}{N} \sum_{n=0}^{N-1} V(n) e^{-j \frac{2 \pi k n}{N}} \text { for } k=0,1,2, . . N-1
$$

Where $\mathrm{V}_{\mathrm{k}}$ is the phasor and the sampling angle, $\theta=2 \pi / \mathrm{N}=2 \pi f_{0} \tau$ for sampling interval $\tau$ with nominal power system frequency $f_{0}$. Note the frequency $\omega$ appear in the DFT at $\pm \omega$ can be combined, which introduces a factor 2 in front of the summation. The (4) is the phasor representation of the voltage input signal estimated by the DFT in one period of data window. It is worthwhile to mention that the PMU generally produces standard outputs with positive sequence phasors.

Assuming, $t=0$ is the time at which the measurement is being started, see Figure 1, the PMU computes the phasor as given by (4) utilizing the digital data of the input signal. The (4) represents a nonrecursive phasor measurement in a one period of fixed-length data window. It is to be noted that each time a new phasor is generated when a new sample is acquired in a data window. The continuous monitoring of this data can be handled efficiently through recursive algorithm. In recursive form the computation of phasor for each data window is done by repeating the (4) in identical fashion. Let $V_{k}$ represents the phasor for the sampled data set $V(n)\{n=k, k+1, \ldots, N+k-1\}$, let a new measurement is taken to generate a new set of data $V(n)\{n=k+1, k+2, \ldots, N+k\}$. Therefore, the phasor for the new data window can be computed as:

$$
V_{k+1}=V_{k}+\frac{\sqrt{2}}{N}[V(N+k)-V(k)] e^{-j k \frac{2 \pi}{N}}
$$
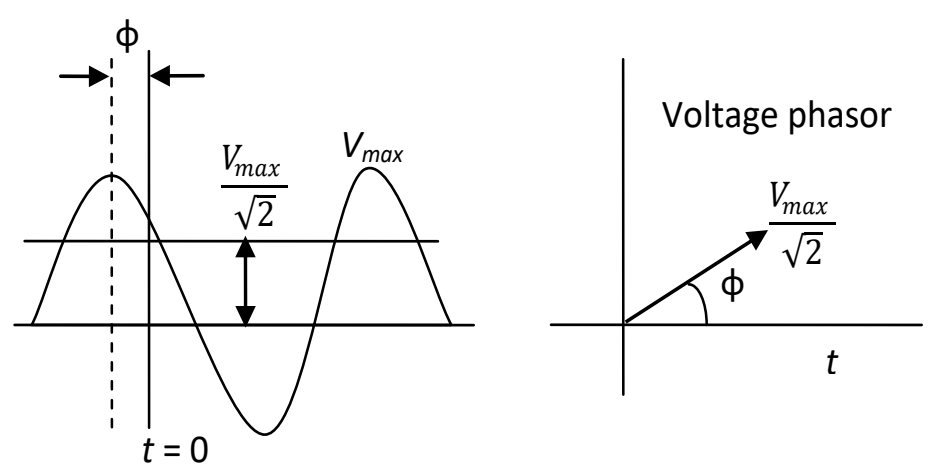

Figure 1. Voltage signal and its phasor diagram

It is evident that the recursive formulation (5) is simple and it involves computation of only two samples: $V(N+k)$ and $V(k)$ but in the non-recursive formulation (4) computations are performed with $N$ 
samples. A practical sampling rate around 16 times $\left(f_{s}=16 f_{0}\right)$, of the standard power system frequency, $f_{0}=50 \mathrm{~Hz}$ gives sampling frequency $f_{s}=800 \mathrm{~Hz}$, which generates $N=16$ samples in one period of the input signal. In Radix-2, fast Fourier transformation (FFT) algorithm requires $\left(N=16=2^{4}\right)$ 4-stages of butterfly computation. It is possible to perform this task online with the help of digital signal processor (DSP). It is customary to mention that in a smart substation, all measurement signals will be time synchronized with high accuracy via GPS signal. The estimation of the substation parameters are considered to be achieved through synchronized phasor measurement (SPM) technology. Therefore, it is feasible to represent the phasors of all remote signals in a same phasor diagram by synchronization of their sampling process. Thus, monitoring and control of wide area signals can be possible with this technology with high fidelity from remote control centre as shown in Figure 2.

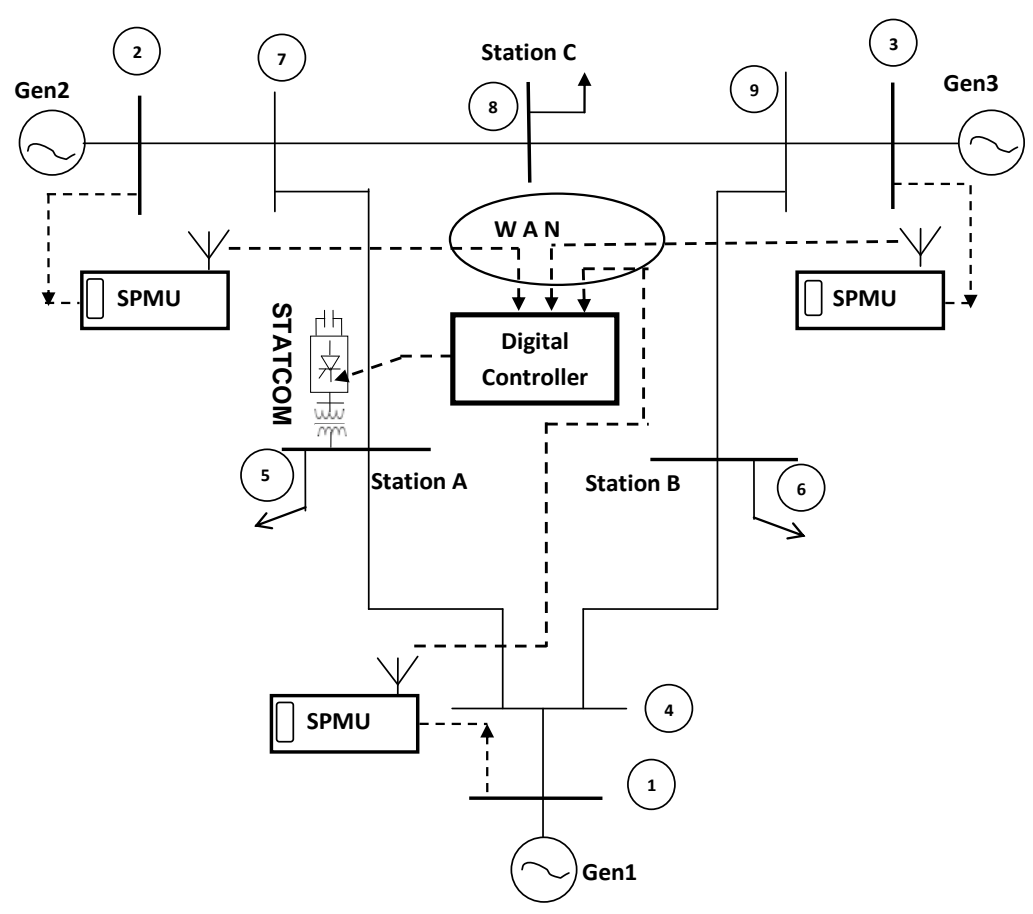

Figure 2. Application of SPMU in wide area application

\subsection{Synchronizing phasor measurement unit (SPMU)}

The functional blocks for a typical SPMU are demonstrated in Figure 3. The SPMU uses time synchronizing measured variables from GPS system. The acquired GPS wave is transformed to an acceptable intermediate frequency (IF) in the front end GPS receiver, and then refined by the phasor microprocessor. The power station GPS receiver is assumed to be located at point $X$, where three spheres with radii $R_{1}, R_{2}, R_{3}$ intersect as shown in Figure 4.

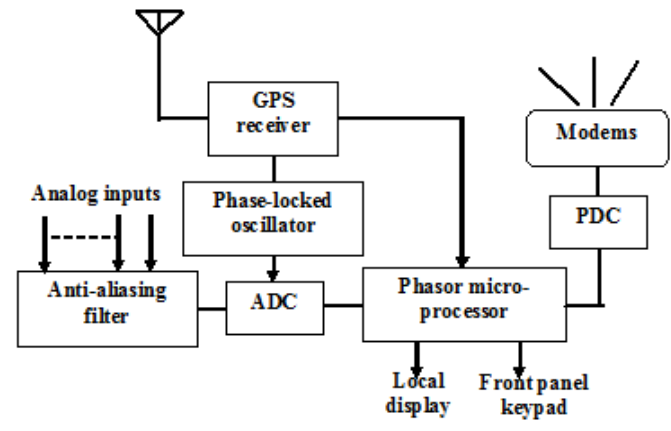

Figure 3. Synchronizing phasor measurement unit

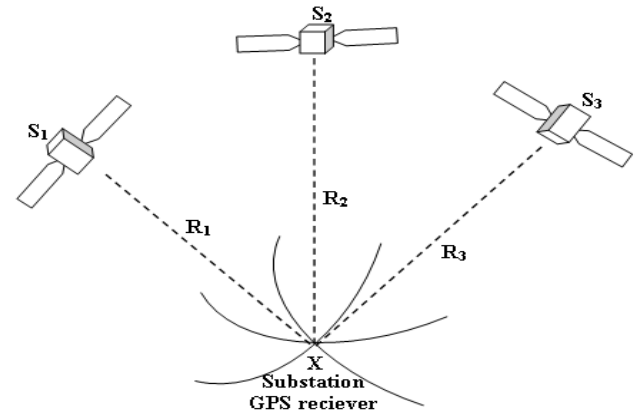

Figure 4. Substation GPS measurement (SPMU) 
The GPS receiver generates the 1 pulse-per-second (pps) signal and a time tag, which may consists of the year, day, hour, minute, and second. The l-pps signal is converted into the required number of pulses with a phase-locked oscillator for sampling of the analog input. The microcontroller computes the positive sequence phasors using the recursive algorithm (5). The computed string of phasors, one for each of the positive sequence measurements, is assembled in a phasor data concentrator (PDC) and this phasor data stream from PDC is then transmitted through a dedicated communication network at a rate of about every 2-5 cycles (40-100 msec) of the fundamental power system frequency $(50 \mathrm{~Hz})$. As the power system dynamic problems are usually initiated in the low frequency range $(0.2-2.5 \mathrm{~Hz})$, therefore it is possible to study in realtime the problem of dynamic instability reliably at the control point.

\section{DESIGN OF ANALOG AND DIGITAL STATCOM CONTROLLER}

\subsection{Prototype schematic of STATCOM controller}

The STATCOM controller prototype as a voltage controller is sketched in the Figure 5 [26]. The STATCOM in conjunction with only a voltage control device is not sufficient to dampen every undammed modes of the whole system. Thus, it is usual practice to incorporate a supplementary control in addition with the STATCOM voltage regulator. As the generator speed captures the effect of every undammed mode, therefore, the speed deviation signal of the generator can be utilized as the supplementary control action signal for the STATCOM.

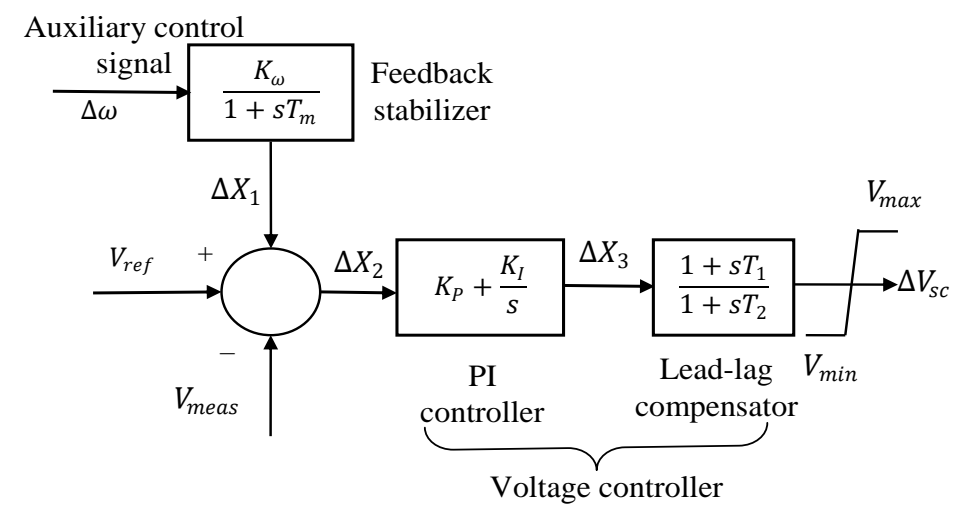

Figure 5. STATCOM voltage controller

The block-diagram of the STATCOM voltage controller, see Figure 5, can be written under mentioned state in (6-8):

$$
\begin{aligned}
& \Delta \dot{X}_{2}=-\frac{1}{T_{m}} \Delta X_{2}+\frac{K_{\omega}}{T_{m}} \Delta \omega-\frac{1}{T_{m}} \Delta V_{\text {meas }} \\
& \Delta \dot{X}_{3}=\left(-\frac{K_{P}}{T_{m}}+K_{I}\right) \Delta X_{2}+\frac{K_{P} K_{\omega}}{T_{m}} \Delta \omega-\frac{K_{P}}{T_{m}} \Delta V_{\text {meas }} \\
& \Delta \dot{V}_{s c}=-\frac{1}{T_{2}} \Delta V_{s c}+\frac{1}{T_{2}} \Delta X_{3}+\frac{T_{1}}{T_{2}}\left(-\frac{K_{P}}{T_{m}}+K_{I}\right) \Delta X_{2}+\frac{T_{1} K_{P} K_{\omega}}{T_{2} T_{m}} \Delta \omega-\frac{T_{1} K_{P}}{T_{2} T_{m}} \Delta V_{\text {meas }}
\end{aligned}
$$

\subsection{Installation of STATCOM for a multigenerator power system}

The two-axis linearized model of a multigenerator power network connecting basic power system components respectively exciter and power transmission networks have been described in [27]. This model can be presented as:

$$
\begin{gathered}
\Delta \dot{X}=A_{1} \Delta X+B_{1} \Delta I_{g}+B_{2} \Delta V_{g}+E_{1} \Delta U \\
0=C_{1} \Delta X+D_{1} \Delta I_{g}+D_{2} \Delta V g
\end{gathered}
$$




$$
\begin{aligned}
& 0=C_{2} \Delta X+D_{3} \Delta I_{g}+D_{4} \Delta V_{g}+D_{5} \Delta V_{l} \\
& 0=D_{6} \Delta V_{g}+D_{7} \Delta V_{l}
\end{aligned}
$$

Here, (9) and (10) constitute the machine dynamic equations in linearized form and (11) and (12) depict the equations for the network correspond to the PV buses and the PQ buses respectively. The application of a STATCOM in the above system consequences insertion of state variables, $\Delta X_{\text {Statcom }}=\left[\begin{array}{lll}\Delta X_{2} & \Delta X_{3} & \Delta V_{S c}\end{array}\right]^{T}$ with the machine DAE in (9-10) and the power flow equations of the STATCOM in the network equations (11)-(12). If it is assumed that the STATCOM is connected to any $j$-th load bus. The power flow equations of a STATCOM can be obtained as:

$$
\begin{aligned}
& P_{s c}=\left|V_{s c}\right|^{2} G_{s c}-\left|V_{s c}\right|\left|V_{j}\right|\left[G_{s c} \cos \left(\delta_{s c}-\theta_{j}\right)+B_{s c} \sin \left(\delta_{s c}-\theta_{j}\right)\right] \\
& Q_{s c}=-\left|V_{s c}\right|^{2} B_{s c}-\left|V_{s c}\right|\left|V_{j}\right|\left[G_{s c} \sin \left(\delta_{s c}-\theta_{j}\right)-B_{s c} \cos \left(\delta_{s c}-\theta_{j}\right)\right]
\end{aligned}
$$

where, $V_{s c} \angle \delta_{s c}=$ STATCOM output voltage (ac) and $Y_{s c}=G_{s c}+j B_{s c}$. All symbols have their usual significances. Therefore, the active and reactive power flow equations corresponding to the load bus ' $j$ ' in linearized form are given by (15). It has been further assumed that participation of the other load buses remain unchanged.

$$
\left[\begin{array}{c}
\Delta P_{j} \\
\Delta Q_{j} \\
\Delta P_{s c} \\
\Delta Q_{s c}
\end{array}\right]=\left[\begin{array}{llll}
\frac{\partial P_{j}}{\partial \theta_{j}} & \frac{\partial P_{j}}{\partial V_{j}} & \frac{\partial P_{j}}{\partial \delta_{s c}} & \frac{\partial P_{j}}{\partial V_{s c}} \\
\frac{\partial Q_{j}}{\partial \theta_{j}} & \frac{\partial Q_{j}}{\partial V_{j}} & \frac{\partial Q_{j}}{\partial \delta_{s c}} & \frac{\partial P_{j}}{\partial V_{s c}} \\
\frac{\partial P_{s c}}{\partial \theta_{j}} & \frac{\partial P_{s c}}{\partial V_{j}} & \frac{\partial P_{s c}}{\partial \delta_{s c}} & \frac{\partial P_{s c}}{\partial V_{s c}} \\
\frac{\partial Q_{s c}}{\partial \theta_{j}} & \frac{\partial Q_{s c}}{\partial \theta_{j}} & \frac{\partial Q_{s c}}{\partial \delta_{s c}} & \frac{\partial Q_{s c}}{\partial V_{s c}}
\end{array}\right]\left[\begin{array}{c}
\Delta \theta_{j} \\
\Delta V_{j} \\
\Delta \delta_{s c} \\
\Delta V_{s c}
\end{array}\right]
$$

Therefore, for a power system network containing $m$ machines and a STSTCOM, the overall system matrix can be equated as:

$$
\left[A \_S t a t\right]_{(7 m+3) \times(7 m+3)}=\left[A^{\prime}\right]-\left[B^{\prime}\right]\left[D^{\prime}\right]^{-1}\left[C^{\prime}\right]
$$

It is to be noted that the elements and dimensions of the sub matrices of (16) will be changed accordingly with the inclusion of the above dynamics of the STATCOM controller. In the successive stages this formulation has been deployed to work out swing modes and identification of critical swing mode in the PSO based optimization method. It is obvious from the Figure 5 that to construct the STATCOM controller there need four calibrated variables; gains for the PI controller $\left(K_{P}, K_{I}\right)$, lead-lag block time constants $\left(T_{1}, T_{2}\right)$. The feedback stabilizer constants $K_{\omega}$ and $T_{m}$ are fixed as 5.0 and 0.5 respectively. In the subsequent division these undecided parameters $\left(K_{P}, K_{I}, T_{1}\right.$ and $\left.T_{2}\right)$ are optimized by virtue of PSO based approach with minimization of a predetermined cost function.

\subsection{Overview of PSO}

The PSO [28] is a heuristic optimization process inspired by the motion and mind of biological flock or school. It is started with a community of arbitrary outcomes and hunts for global optima by upgrading its originations. A 'swarm' comprises of " $n$ " particles which are assumed to be moved in a $D$ dimensional search room. Every particle in a swarm walks in the search room following up its velocity and direction at each step and eventually reached to the target which is corresponding to the best in its flight. This best particle in the community is denoted by (universal best, gbest) and the final position which has been visited by the best particle is designated by (local best, pbest). The PSO achieves the best suited solution by continuous revision of velocity of each particle in the direction of its universal best and local best position. The movement and location of the particles are evaluated by:

$$
v_{i}(n)=\alpha * v_{i}(n-1)+a_{1} * r_{1} *\left(\text { gbest }_{i}-s_{i}(n-1)\right)+a_{2} * r_{2} *\left(\text { pbest }_{i}-s_{i}(n-1)\right.
$$




$$
s_{i}(n)=s_{i}(n-1)+v_{i}(n)
$$

In (17) and (18) velocity of the particle $i$ is designated by $v_{i}(n)$, which is usually considered as $10-20 \%$ of the acceptable span of the variables. $s_{i}(n)$ indicates the location of the $i$ th particle. $a_{1}, a_{2}$ are two scalar coefficients that pull the entire particles towards the universal best and the local best position respectively and their values are generally set in the range $\in(0,2) . r_{1}$ and $r_{2}$ are arbitrary variables with normal distribution with $\operatorname{span} \in(0,1) . \alpha \in(0,1)$ stands for the inertia weight.

\subsection{Strategy of PSO based optimization}

In this section the strategy of PSO based optimization has been outlined. The problem is to find the best fit four unknown parameter $\left(K_{P}, K_{I}, T_{1}\right.$ and $\left.T_{2}\right)$ of the STATCOM controller which has been accomplished through the minimization of a predefined target function defined as optimum damping index $(O D I)$ :

$$
O D I=\eta=\left(1-\beta_{i}\right)
$$

In (19), $\beta_{i}$ denotes the damping ratio of the $i$-th swing mode which is most vulnerable. The $\beta$ and hence ' $\eta$ ' can be calculated from the system matrix and eigenvalues of the multi-machine system with STATCOM controller. The (19) also illustrates the fact that minimization of the desired objective function, $\eta$ can be possible though maximization of the damping ratio $(\beta)$. Any alteration in the four tuning constants of the STATCOM controller, affects the $\beta$, which further changes the above cost function, ODI. The possible bounds for the parameters can be described as follows:

$$
\text { Minimizen } \quad \text { [As in (19)] }
$$

Subject to:

$$
\begin{aligned}
& K_{I}^{\text {min }} \leq K_{I} \leq K_{I}^{\text {max }} ; K_{P}^{\text {min }} \leq K_{P} \leq K_{P}^{\text {max }} T_{1}^{\text {min }} \leq T_{1} \leq T_{1}^{\text {max }} ; \\
& T_{2}^{\text {min }} \leq T_{2} \leq T_{2}^{\text {max }}
\end{aligned}
$$

\subsection{Implementation of PSO method}

This section implements PSO based optimization process using MATLAB toolbox, 'PSO toolbox' [29]. In this toolbox 'pso_Trelea_vectorized.m' is the main execution program which utilizes a bunch of subprograms to run the complete optimization process. To evaluate the function $(\eta)$ given in (19), the user created eigenvalue computation program has been called in the main program. In this problem the 'particle' has been customized through a vector comprising with four regulating parameters of the controller which can be represented by:

$$
\text { Particle }=\left[\begin{array}{llll}
K_{P} & K_{I} & T_{1} & T_{2}
\end{array}\right]
$$

The optimization process starts with random initialization of populations of the individual particle. The spans of the vector elements given in (20) are specified in Table 1. To compute the objective function ' $\eta$ ' the custom built eigenvalue estimation program of the multimachine system as shown in Figure 2 runs for each particle. The values for the particle vector updates for each run and execution continues until reaches convergence. At the point of convergence PSO returns the best values of the controller variables and the objective function which are displayed in Table 1. The rate of minimization of the objective function towards optimal results for particle numbers 10 with generation size 150 is shown by the Figure 6 . It has been noticed that the convergence is ensured about at generation step 40 and hold up to the last limit of the generation.

Table 1.Variables for STATCOM controller and PSO based results

\begin{tabular}{lrrrrr}
\hline Controller parameters & \multicolumn{2}{c}{$\begin{array}{r}\text { Typical span for the parameters } \\
\text { (Low }\end{array}$} & $:$ & PSO generated value & ODI $(\eta)$ \\
\hline$K_{P}$ & $(0.1$ & $:$ & $10.0)$ & 8.5329 & \\
$K_{I}$ & $(0.1$ & $:$ & $2.00)$ & 1.0211 & \\
$T_{1}$ & $(0.1$ & $:$ & $1.50)$ & 0.5679 \\
$T_{2}$ & $(0.01$ & $:$ & $0.25)$ & 0.0100 & \\
\hline
\end{tabular}

Int JAppl Power Eng, Vol. 10, No. 1, March 2021: $30-40$ 


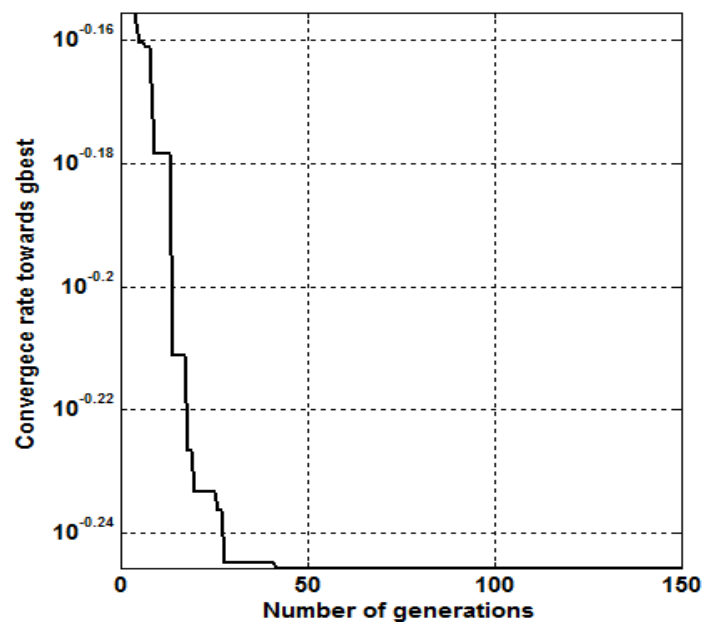

Figure 6. Minimization rate of the desired objective function

\subsection{Digital STATCOM controller}

The SPMU based voltage phasors measured from different substations are digital signals which are unable to process by the analog controller as shown in Figure 5. Again the direct design of higher order digital controller for a multimachine system is quite complicated. Therefore the PSO based continuous-time analog controller is converted to digital one via bi-linear (Tustin's) transformation. Hence if " $s$ " is substituted by the term:

$$
s=\frac{2}{\tau} \frac{1-\mathrm{z}^{-1}}{1+\mathrm{z}^{-1}}
$$

In the continuous-time controller model shown in Figure 5, the resulting controller will be the digital controller. The schematic layout for the discrete-time STATCOM controller is depicted in Figure 7. The controller receives DSP based outputs, $V_{\text {meas }}(k)$ from different SPMUs installed with the generator buses. The controller generates control action signal $V_{s c}(k)$ which has to be processed further through " $\mathrm{ZOH}$ " before implementation to a continuous-time study power system.

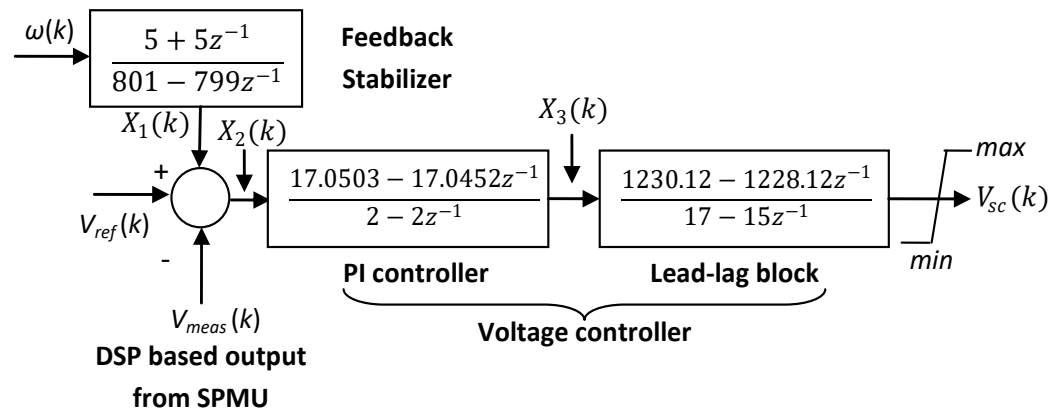

Figure 7. Digital STATCOM controller

\section{PERFORMANCE EVALUATION}

In this section performance of both the analog and digital controllers are investigated for a step change in machine speed deviation. The step response and time-depended synthesis of the system are performed in MATLAB environment. The rotor speed deviation response of generator \#1, generator \#2 and generator \#3 are calculated and plotted separately in Figures 8(a), 8(b) and 8(c) respectively for an analysis time $7 \mathrm{sec}$. It has been found that performances of both the controllers are satisfactory and they are suitable for improvement of instability phenomenon of the power system. However, it appears that digital STATCOM controller is capable to induce major damping in the speed deviation response and can brings the system quickly to the steady state condition against transient disturbances. 
Figure 8 also clearly indicating the facts that peak overshoots and the settling time is substantially improved in each study case with application of the digital controller compared to the case of continuoustime controller. It has been further observed that both the controller imparted better response in generator \#3 compared to the response observed in generator \#1 and generator \#2. In the response of generator \#3 it is noticeable that overshoots and undershoots are occurring less in numbers and the system also reaches quickly to the steady state condition within $3 \mathrm{sec}$. Therefore, from the simulation results presented in Figure 8 , it is viable to suggest that the digital STATCOM controller is more effectual in respect to the continuous-time analog controller in mitigating dynamic instability problems in a power system.

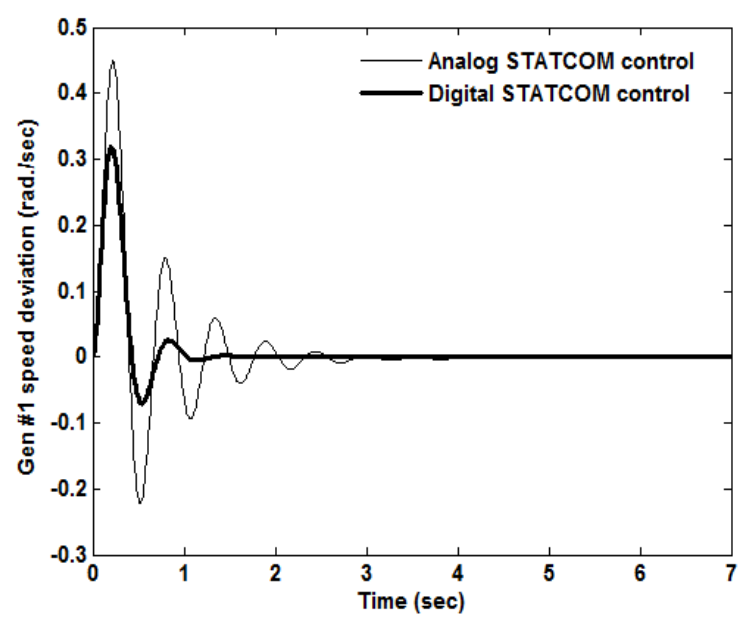

(a)

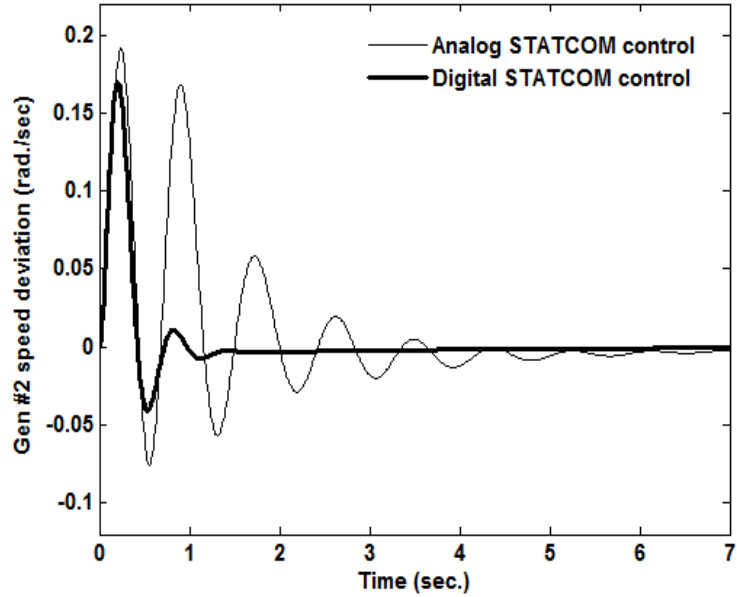

(b)

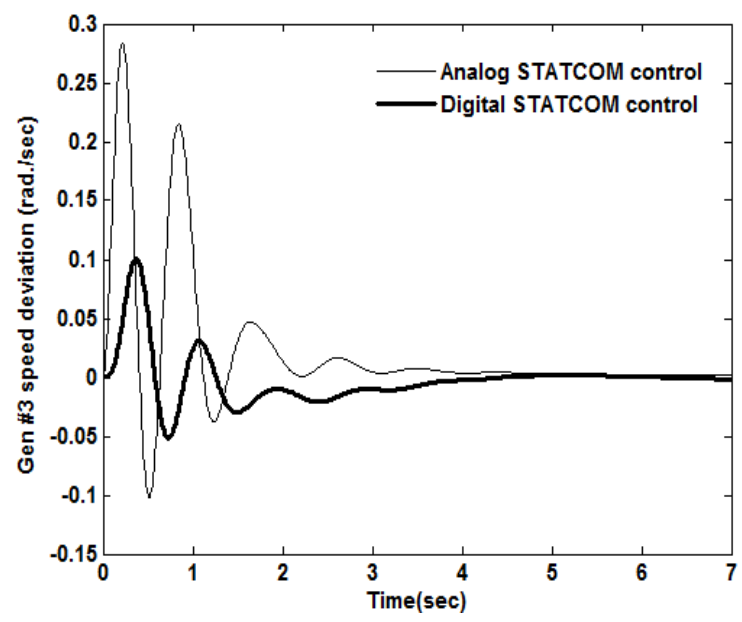

(c)

Figure 8. Dynamic profile of generator speed response, (a) generator \#1, (b) generator \#2, (c) generator \#3

\section{CONCLUSION}

In this work the idea of synchronizing phasor measurement and its utilization for power system stability enhancement has been described. The PMU are strategically placed in a multimachine power system in decentralize manner. A PI type lead-lag STATCOM controller along with SPM unit is employed to inquire the dynamic instability problem of a multimachine power system. The analog model for the STATCOM controller is optimized by the PSO based optimization method. As the discrete time signal obtained from phasor measurement unit is unsuitable for processing by the analog controller, it is then converted to digital one with the help of Tustin's transformation. The intension of Tustin's transformation in digital control design is that direct design of digital control is a trivial task and the processing of infinite samples of impulse 
response is practically not possible. Another objective of the author is to examine the performance of the digital control and the analog control for the particular task of interest in the manuscript. It has been established that the digital control set-up is substantially successful and superior than the analog control. The relevancy of the application of PMU is that implementation of DSP based control in wide area monitoring (WAM) for a multi area power system network. It is to be noted that the limitation of the wide area control like signal latency or transmission delay is not considered here by the author. The present work can be extended further considering signal transmission delay. The proposed plan can also be adopted considering different FACTS controller for some other multimachine power systems.

\section{REFERENCES}

[1] P. Kundur, M. Klein, G. J. Rogers, and M. S. Zywno, "Application of power system stabilizers for enhancement of overall system stability," in IEEE Transactions on Power Systems, vol. 4, no. 2, pp. 614-626, 1989.

[2] N. G. Hingorani and L. Gyugyi, "Understanding FACTS: Concepts and technology of flexible AC transmission systems," New Jersey: Wiley-IEEE Press, 2000.

[3] S. do Nascimentoa and M. M. Gouvêa Jr., "Voltage stability enhancement in power systems with automatic FACTS device allocation," Energy Procedia, vol. 107, pp. 60-67, 2017.

[4] M. Nagaraju, V. V. K. Reddy, and M. Sushama, "Wavelet based performance analysis of AC transmission systems with unified power flow controller under power quality issues," International Journal of Applied Power Engineering, vol. 8, no. 3, pp. 299-308, 2019.

[5] D. Chatterjee and A. Ghosh, "Improvement of transient stability of power system with STATCOM-controller using trajectory sensitivity," International Journal of Electric Power and Energy System, vol. 33, no. 3, pp. 531-539, 2011.

[6] E. C. Barrera, L. E. C. Ugalde, and O. B. Ramos, "Design of a digital control system for a PWM-based STATCOM," 2009 IEEE Electrical Power \& Energy Conference (EPEC), Montreal, QC, pp. 1-6, 2009.

[7] F. R. Mehdizadeh and D. Nazarpour, "An STATCOM-based Hybrid Shunt Compensation scheme capable of damping subsynchronous resonance," International Journal of Applied Power Engineering, vol. 6, no. 3, pp. 150159, 2017.

[8] L. Xu, V. G. Agelidis and E. Acha, "Development considerations of DSP-controlled PWM VSC-based STATCOM," in IEE Proceedings - Electric Power Applications, vol. 148, no. 5, pp. 449-455, 2001.

[9] R. Doraiswami and A. M.Sharaf, "Digital controller design for enhancing steady-state stability of interconnected power systems," International Journal of Electric Power and Energy System, vol. 7, no. 4, pp. 210-214, 1985.

[10] A. G. Phadke, J. S. Thorp and M. G. Adamiak, "A new measurement technique for tracking voltage phasors, local system frequency, and rate of change of frequency," in IEEE Transactions on Power Apparatus and Systems, vol. PAS-102, no. 5, pp. 1025-1038, 1983.

[11] P. Nanda, C. K. Panigrahi, and A. Dasgupta, "Phasor estimation and modelling techniques of PMU- A Review," Energy Procedia, vol. 109, pp. 64-77, 2017.

[12] B. Singh, N. K. Sharma, A. N. Tiwari, K. S. Verma and S. N. Singh, "Applications of phasor measurement units (PMUs) in electric power system networks incorporated with FACTS controllers," International Journal of Engineering, Science and Technology, vol. 3, no. 3, pp. 64-82, 2011.

[13] N. R. Chaudhuri, B. Chaudhuri, S. Ray, and R. Majumder, "Wide-area phasor power oscillation damping controller: A new approach to handling time-varying signal latency," in IET Generation, Transmission \& Distribution, vol. 4, no. 5, pp. 620-630, 2010.

[14] M. T. Khan and A. S. Siddique, "FACTS device control strategy using PMU," Perspectives in Science, vol. 8, pp. 730-732, 2016.

[15] B. V. Prasanth and S. V. J.Kumar, "New robust fuzzy load frequency controller for a two area interconnected power system," Journal of Theoretical and Applied Technology, vol. 5, no. 2, pp. 242-252, 2009.

[16] H. E. A.Talat, A. Abdennour, and A. A.Al-Sulaiman, "Design and experimental investigation of a decentralized GA-optimized neuro-fuzzy power system stabilizer," Int. Journal of Electrical Power and Energy Systems, vol. 32, no. 7, pp. 751-759, 2010.

[17] R. Poli, J. Kennedy, and T. Blackwell, "Particle swarm optimization: An overview," Swarm Intelligence, vol. 1, no. 1, pp. 33-57, 2007.

[18] D.Mondal, A. Chakrabarti, and A.Sengupta, "Optimal placement and parameter setting of SVC and TCSC using PSO to mitigate small signal stability problem," International Journal of Electric Power and Energy System, vol. 42, no. 1, pp. 334-340, 2012.

[19] C. Mishra, K. D. Jones, A. Pal, and V. A. Centeno, "Binary particle swarm optimisation-based optimal substation coverage algorithm for phasor measurement unit installations in practical systems," in IET Generation, Transmission \& Distribution, vol. 10, no. 2, pp. 555-562, 2016.

[20] A. G. Phadke and BI. Tiansgu, "Phasor measurement units, WAMS, and their applications in protection and control of power systems," J. Mod. Power Syst. Clean Energy, vol. 6, pp. 619-629, 2018.

[21] N. P. Theodorakatos, N. M. Manousakis, and G. N. Korres, "Optimal placement of phasor measurement units with linear and non-linear models," Electric Power Components and Systems, vol. 43, no. 4, pp. 357-373, 2015.

[22] N. M. Manousakis, G. N. Korres, and P. S. Georgilakis, "Taxonomy of PMU Placement Methodologies," in IEEE Transactions on Power Systems, vol. 27, no. 2, pp. 1070-1077, 2012. 
[23] N. C. Koutsoukis, N. M. Manousakis, P. S. Georgilakis, and G. N. Korres, "Numerical observability method for optimal phasor measurement units placement using recursive Tabu search method," in IET Generation, Transmission \& Distribution, vol. 7, no. 4, pp. 347-356, 2013.

[24] A. Ahmadi, Y.Alinejad-Beromi, and M.Moradi, "Optimal PMU placement for power system observability using binary particle swarm optimization and considering measurement redundancy," Expert Systems with Applications, vol. 38, no. 6, pp. 7263-7269, 2011.

[25] A. G. Phadke and J. Thorp, "Synchronized phasor measurements and their applications," Springer: New York, 2008.

[26] K. R. Padiyar, "Analysis of sub-synchronous resonance in power systems," Kluwer Academic Publishers: Norwel, 1999.

[27] D. Mondal, A. Chakrabarti, and A. S.Mondal, "Power system small signal stability analysis and control," Elsevier Inc. Academic Press, Elsevier S \& T book division, 2020.

[28] J. Kennedy and R. Eberhart, "Particle swarm optimization," Proceedings of ICNN'95 - International Conference on Neural Networks, Perth, WA, Australia, 1995, pp. 1942-1948 vol.4.

[29] B. Birge, "Particle swarm optimization toolbox," 2006. [Online]. Available at: www.mathworks.com.

\section{BIOGRAPHY OF AUTHOR}

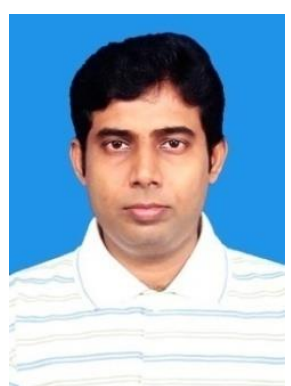

Debasish Mondal received his bachelor of technology and master of engineering degrees in 1998, 2000 form University of Calcutta and Indian Institute of Engineering Science \& Technology (IIEST), India [Formerly: Bengal Engineering \& Science University (BESU)] respectively. He did Ph.D in engineering in 2012 from the Department of Electrical Engineering, IIEST. He has around 20 years of teaching and research experience and has 41 research publications in different international journals and conferences. He is an author of book, Power System Small Signal Stability Analysis and Control: Elsevier Sc. \& Tech. Publication. He has worked around 06 years as an Assistant Engineer in Hindustan Paper Corporation Ltd. (A Govt. of India Enterprise). He was formerly associated with Haldia Institute of Technology, Haldia, India. At present he holds a post of associate professor \& HOD in the Department of ElectricalEngineering, RCC Institute of Information Technology, Kolkata, India. His active research interests on the areas like power systems stability, soft computing, robust control, nonlinear control systems, and optimal control systems. He is a member of editorial team of different international \& peer reviewed journals. Dr. Mondal is a Member of IEEE-CSS (M93436525) and Life Member of IE(I) (LM-1514878), ISTE (I) (LM-112889) and The Robotic Society (TRS) of India. (LM-191112). 